\title{
Design Thinking and Cognitive Science: An Exploratory Approach to Create Intellectual Capital with Decentralised Organisations
}

\author{
Salim Chujfi \\ Hasso Plattner Institut \\ Potsdam, Germany \\ salim.chujfi@hpi.de
}

\author{
Christoph Meinel \\ Hasso Plattner Institut \\ Potsdam, Germany \\ christoph.meinel@hpi.de
}

\begin{abstract}
The significance of managing intellectual capital within organisations so as to be competitive in the digital age, combined with the distributed or discontinuous essence of geographically decentralised organisational forms, places enormous challenges on today's business leaders who want to retain control of the knowledge created dispersedly. This analysis explores a cyber-humanistic approach to improve the effectiveness of interaction in distributed settings, based on individual cognitive preferences, addressing the management of intangible tacit knowledge to develop intellectual capital. We aligned elements of the Japanese Style of global organisational knowledge creation and Design Thinking to develop a context to identify cognitive values of a descentralized organisation style. It provides individuals and teams with the grounds to effectively function in order to produce quality work that can be assessed as capital. The improved interaction scheme aims to create intellectual capital, aligning staff personalities that are cognitively sympathetic improving information gathering and creating business value.
\end{abstract}

\section{INTRODUCTION}

$\mathrm{T}$ HE idea that we are capable of producing extraordinary quantities of data is not new. The quantity of digital data is growing exponentially and is astronomically vast, however, having more data does not necessarily mean that we are processing it entirely, nor making proper use of it transforming it in something valuable for individuals or organizations.

The opportunities of having more data enable organisations to do things differently and indeed to profit from this. The transformation of data into knowledge, and its further refinement of transforming knowledge into intelligence, needs to be addressed independently, as suggested in Figure 1, which is an adaptation of the DIKW Pyramid of Ackoff [1]. Firstly, to transform data into information, basic categorisations and sorting are necessary to segment information according to any given parameter. Secondly, to transform information into knowledge, it is possible to apply Big-Data algorithms to convert defined signals, records and other different sources of classified data to improve efficiency, detect patterns, resolve problems and provide new perspectives on the world around us. Nevertheless, the final step, the transformation of knowledge into intelligence, requires, to a certain degree, creativity and human values to take decisions, innovate and thus create intellectual capital.

This research focuses specifically in how to cognitively improve the last step of the chain, transforming knowledge into intelligence and increase the generation of intellectual capital. In order to achieve that, a crucial prerequisite is to understand that the digital literacy of organizations means much more than just a number of technological skills their employees can master. Rather, it is synonymous with a new Cyber Cognition that encompasses a variety of motor, emotional, cognitive and sociological behavioural adaptations: competencies that enable people to function in digital environments. Cyber Cognition is a paradigm that shifts interaction from an exclusively technology-based context to consider in addition individual cognitive preferences and digital literacy.

Intellectual capital in the digital world relies on the ability of individuals or groups to share knowledge online with others, whereas the interaction involves identifying with others and distinguishing ourselves from others. Considering differences and similarities between individuals, their interests and expertise, the use of cognitive and behavioural instruments online is also necessary to allow the monitoring and guiding characteristics of team members to identify preferred and compatible modes and styles of interaction. It allows better communication that produces valuable outputs that organizations can materialize and retain in new ideas or products.

Another important factor to consider is that the creator of the intellectual capital in the digital world needs an online identification (the online self), which, in our context, is viewed by others. It develops, interacts, takes form, and works with other online users. Each individual is unique in the digital world, and his/her online self is simply a projection of the cognitive capabilities that allow him/her to interact. 


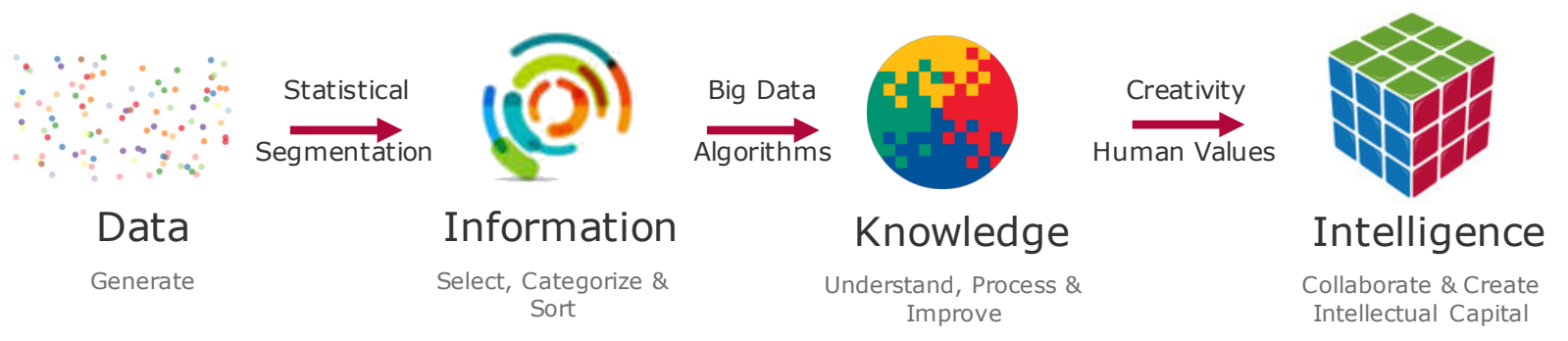

Fig. 1 Extended Data Chain Transformation

To provide a sympathetically grounded interaction to a group of individuals online, this study explores Design Thinking as a context of interaction to be used in the last step of the chain described in Figure 1. Design Thinking is brought into place as a synergy, considering the human as the intellectual (cognitive) generator and multiplicator of intellectual capital. Figure 2 presents the schema proposed for multidisciplinary teams supporting the concept of radical collaboration, enhancing interaction and developing more human contact and trust-based relationships within virtual teams considering cognitive capabilities.

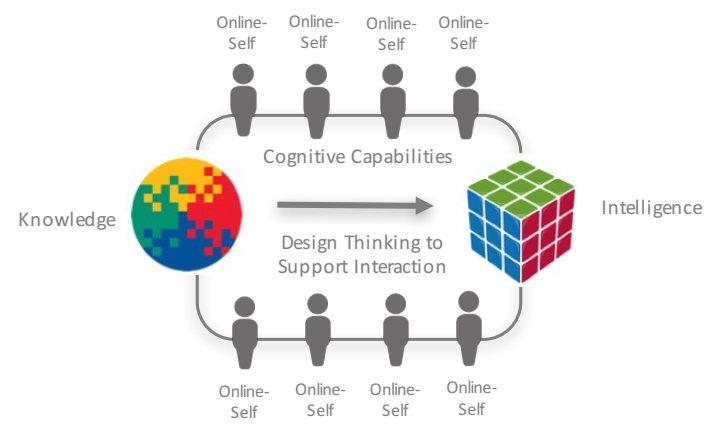

Fig. 2 Cognitive Schema of Virtual Interaction

\section{RELATED WORK}

Several researchers have identified the challenges that decentralised settings engender [2]. The processing of knowledge in the online community requires a methodology to guide the interaction and to support the cyclical cognitivecentred process as a trustable source of sustained competitive advantage. For instance, the influence of trust and the difficulty of building it in decentralised settings has received particular attention [3]. In response, researchers have proposed different approaches. Some of these examine the operational network structure of virtual organisations [4]; and some others investigate the interactions and communication among people within decentralised organisations [5].

One of the most widely recognised problems in knowledge management is that tacit knowledge is difficult to transfer [6][7]. From a communication perspective, this can be explained by the stance that lean (non-face-to-face) communication channels in virtual settings do not provide sufficient support for the necessary transfer of rich information to assist the recipient to acquire tacit knowledge
[8]. This can certainly be considered as an issue related to the use of digital technologies, however it also implies a communication problem that needs to be individually attended [9]. Nevertheless, creating and transferring knowledge are more likely to improve if the communication is supported by a structured method that supports the interaction and data exchange in virtual settings [10].

Researchers have also obtained significant results, indicating that there is evidence for a collective intelligence factor in the performance of human groups [11]. They have established that groups can exhibit a collective intelligence (or c factor) and also develop an analogous "collective" intelligence that could regulate how efficaciously they can address these cognitive assignments. This is a relevant finding to consider, because organizational supervision, and some other kinds of jobs are progressively performed by groups — working both face-to-face and virtually [9]. In order to optimise collective performance, it is therefore required to comprehend what defines a group more intelligent. This factor is not related to cohesion, motivation or satisfaction, but to the average social sensibility [9]. This has given us a new path by which to examine cognitive dimensions more intensively.

Interaction plays an important role as well since it helps developing communities, and the feeling of engagement for the individuals and the group, leading to the development of the social knowledge fabric [9]. The feeling of belonging and experiencing social networks can stimulate people sense of trust and tolerance. The concept of social capitalism is presented as the formal medium to collect any current or potential knowledge which is related to ownership of a robust network of more or less established relationships with mutual awareness and recognition [12].

Despite several social and rational dimensions of knowledge management having been analysed by researchers, considering the learning processes of an organisation, how knowledge is represented and how IT systems manage their transformation, the cognitive dimensions of individuals and their values are still not substantially considered, and very little has been studied in regard to the human-centred discussion considered in geographically decentralised teams. 


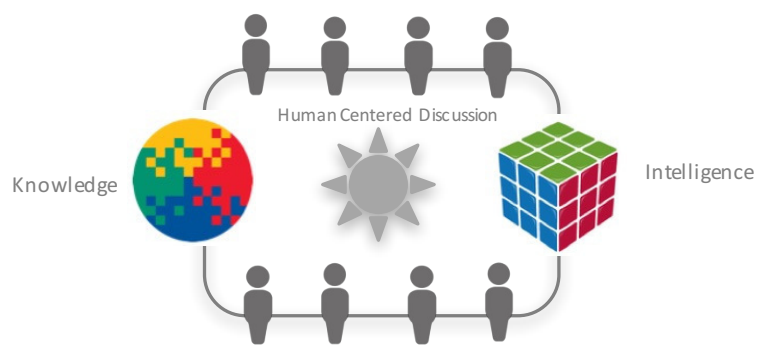

Fig. 3 Knowledge Transformation Schema

\section{ORGANIZATIONAL INTELLECTUAL CAPITAL}

Considering the creation of intellectual capital with particular attention to the relation between human-centered discussions and collective thinking, we started studying knowledge management approaches that are radically different, and which take place on a global scale. We reviewed and summarized in Table 1, the Japanese Style Knowledge management and compared it to the Western approaches, following the premises suggested by Nonaka \& Takeuchi [13]. The target was to identify the different core elements of both styles that could be particularly cognitively relevant for geographically distributed communities where individuals are challenged to have a particular digital environment of interaction. Considering how multidisciplinary geographically decentralised teams are built, we validated particularly three aspects which need to support the cognitive dimensions of interaction between the actors thanks to the human-centred discussion it drives.

\section{A. The Interaction between Tacit and Explicit Knowledge}

In the West, interaction between tacit and explicit knowledge takes place at the individual level. Concepts and ideas tend to be created through externalisation efforts coming from top managers, or through the creation of innovative products, which are then combined organisationally into new admirable personalities or archetypes of new products. In Japan, however, the interaction between tacit and explicit knowledge usually takes place at the group level. Knowledge-creation project teams are led by middle managers, who play a key role in sharing tacit knowledge among the team, considering all the relevant information, such as advanced concepts coming from top managers, or from front-line members who directly interact with the world offering services or products. The intensive human interaction produces a wide range of novel concepts for developing target products, services and business systems. This is an analogous approach to what Design Thinking defines as an "iterative process".

\section{B. Thinking Skills (externalisation and socialisation)}

Analytical thinking skills and concrete forms of oral and visual presentation, such as manuals, documents and databases, are commonly used by Western business organisations. Western leaders' strengths are mostly based on externalisation and combination, which could riskily trap them into the so-called "paralysis by analysis" syndrome. The state of over-analysing or over-thinking a situation, so that decisions or actions are never taken, in effect paralyse the outcome. Japanese, on the other hand, tend to rely heavily on tacit knowledge. They use intuition, figurative and sometimes ambiguous - language and are relatively weak in analytical skills. To compensate for this, they seek interaction and discussion among people (socialisation) as much as they can. The Japanese Style of knowledge creation is internationalisation. As soon as an archetype is created, high-quality tacit knowledge is quickly accumulated at individual and organisational levels by mass-producing or implementing an archetype. The style of Japanese knowledge creation can lead to what is called "collective thinking". This approach is what Design Thinking proposes as "radical collaboration".

\section{Organisational Intentions and Ambiguities}

Western-style intellectual capital creation relies on clear organisational intentions, a low redundancy of information and tasks, low fluctuation from top management and high autonomy at the individual level. In contrast, Japanese-style intellectual capital creation is characterised by relatively ambiguous organisational intention, frequent fluctuation from top management and high autonomy at the group level. The dynamic that Design Thinking offers mimics the Japanese Style, as it does motivate constant re-thinking of new contrasting approaches, and also relies on the autonomy of the cluster groups commonly defined in each of the sessions.

Additional to the previous three aspects on how the knowledge-creation process differ between Japanese and Western, we proceeded to summarise in Table 1 some relevant aspects particularly considering the individual and his interaction in the environment within the organization.

TABLE 1:

DiFFERENCE BETWEEN JAPANESE AND WESTERN KNOWLEDGECREATION PRACTICES [13]

\begin{tabular}{l|l}
\hline \multicolumn{1}{c|}{ Japanese Organisation } & \multicolumn{1}{c}{ Western Organisation } \\
\hline Group-based & Individual-based \\
\hline Tacit knowledge-oriented & Explicit knowledge-oriented \\
\hline $\begin{array}{l}\text { Strong socialisation and } \\
\text { internationalisation }\end{array}$ & $\begin{array}{l}\text { Strong externalisation and } \\
\text { combination }\end{array}$ \\
\hline Emphasis on experience & Emphasis on analysis \\
\hline Danger of group thinking & $\begin{array}{l}\text { Danger of "paralysis by } \\
\text { analysis" }\end{array}$ \\
\hline $\begin{array}{l}\text { Ambiguous organisational } \\
\text { intention }\end{array}$ & Clear organisational intention \\
\hline Group autonomy & Individual autonomy \\
\hline
\end{tabular}




\begin{tabular}{l|l}
\hline $\begin{array}{l}\text { Creative chaos through } \\
\text { overlapping tasks }\end{array}$ & $\begin{array}{l}\text { Creative chaos through } \\
\text { individual differences }\end{array}$ \\
\hline $\begin{array}{l}\text { Frequent fluctuation from top } \\
\text { management }\end{array}$ & $\begin{array}{l}\text { Less fluctuation from top } \\
\text { management }\end{array}$ \\
\hline Redundancy of information & Less redundancy of information \\
\hline $\begin{array}{l}\text { Requisite variety through cross- } \\
\text { functional teams }\end{array}$ & $\begin{array}{l}\text { Requisite variety through } \\
\text { individual differences }\end{array}$ \\
\hline
\end{tabular}

We identify in Table 1 how some fundamental concepts from the Japanese Style that can be supported online with the application of Design Thinking. For instance, strong socialization through human-centred discussion, creative chaos through the culture of prototyping and crossfunctional teams through radical collaboration. As represented in Figure 4, we take the effectiveness human centered discussion of the Japanese Style as reference to build up the interaction framework supported in Design Thinking, which we proceed now to model as an intellectual capital driver in virtual teams.

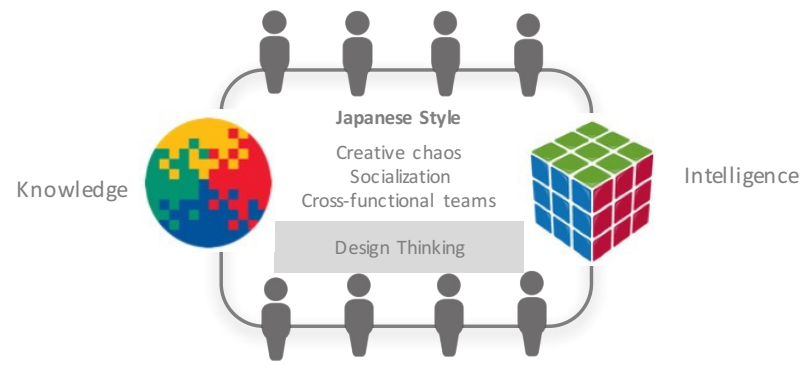

Figure. 4 Knowledge and Interaction with Design Thinking

\section{DESIGN THINKING}

The Japanese Style of intellectual capital creation and its effectiveness could be materialised in geographically decentralised organisations with the aid of Design Thinking, as it promotes "collective thinking" over "individual thinking", stimulates multidisciplinary human interaction, constantly reflects the creation of archetypes, while ideating prototyping and testing. Thus, the creation of intellectual capital is a shared action of human values between several individuals and is not the product of individual minds working independently. This plays a key role when considering that tacit and multidisciplinary knowledge needs to be transformed into intelligence, while unlocking the creative potential of individuals and including the human values that each participant, independent of its speciality, brings with him/her, as shown in Figure 5.

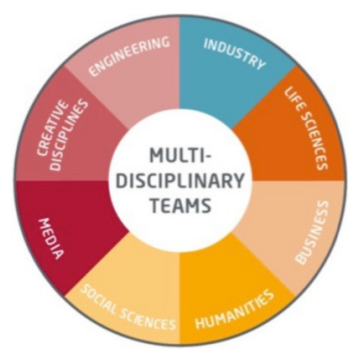

Figure. 5 Interaction of Multidisciplinary Teams [14]
To develop teamwork, it is also necessary for the right combination of leadership and grassroots activism to achieve innovation to scale. Intellectual capital creation in organisations is seldom a solo activity. For the interaction required in each of the Design Thinking stages shown in Figure 5, we propose a systematic approach to cognitively manage the use of information in order to provide a continuous flow of knowledge to the right people at the right time, thus enabling efficient and effective decision-making processes to create business value.

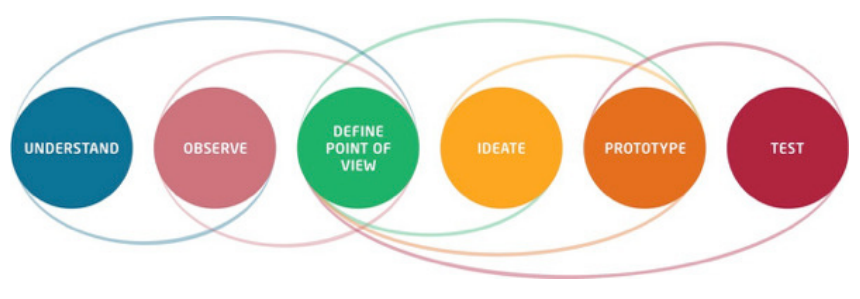

Figure. 5 Design Thinking Stages [14]

To consider Design Thinking as an intellectual capital driver, we base our analysis on the nature of knowledge suggested by Polany's Theory [15], considering that "the knower" requires to actively participate and become a "knower-dependent". Knowledge is a process of individual assembly of data and its elaboration is closely related to the cognitive preferences each individual has [9]. Whenever we express ourselves to communicate what we know, we are able to do it using different channels in different forms. However, messages transmitted can only be interpreted by a knowing mind that can decode and understand them adapting them to its own knowledge structures [16]. Independently of how we process knowledge, it has very little relevance until it is used for some purpose. The main purpose is to realize how individuals' cognitive styles can impact the sharing of knowledge in descentralized and collaborative environments [9].

This means developing properly aligned conditions between human cognition calls for cognitive models dynamic and adaptable computational representations of the cognitive structures and mechanisms.

\section{V.COGNITIVE SCIENCE}

De Bono [17] considered that cognitive styles are required to facilitate a knowledge management system in terms of helping the individual to identify appropriate information and to be able to transfer it at the accurate location.

\section{A. Cognitive Preferences}

Previous researches [9] show that according to Sternberg's Cognitive Theory, people can be understood in terms of the functions, forms, levels, scopes and leanings of governance. However, only three of these: scopes, leanings and levels were identified as relevant to the nature of remote work and virtual teams [18]. 
Levels: Because local cognitive styles prefer concrete detail in their work, whereas global cognitive styles prefer abstract thinking, and remote work elevates ambiguity, people with global cognitive styles will have greater commitment to working with tacit knowledge than people with local cognitive styles. In addition, because the nature of virtual collaboration involves heightened ambiguity from a traditional office setting, these differences are surmised to disproportionately increase the cognitive costs of information exchange for locals during virtual collaboration [19][20]. Thus, people with global cognitive styles will have greater commitment to manage tacit knowledge than people with local cognitive styles.

Scopes: As individuals with internal cognitive styles are more likely to choose to work alone instead of in a group, this would indicate that individuals with those styles would better empathize with environments where less interaction is required, and consequently would this perhaps be related with high levels of commitment to work in virtual environment. [9]. On the other hand, individuals seeking out interaction with their virtual team members have been shown to increase identification with and commitment to coworkers [21]. Thus, people with external cognitive styles will have greater commitment to group interaction than people with internal cognitive styles.

Leanings: As the remote work function has limited capability to support observational modelling, and because it has increased discretion and reduced feedback compared to traditional office settings [22][23][24], working remotely is an activity that is less externally structured. Because similarity between a person's cognitive style and a person's task environment is an important condition for building commitment [25][26], liberals should be more committed to the less structured environment of remote work than conservatives [27]. Thus, people with liberal cognitive styles will have greater commitment to conceptualising and modelling than conservative people.

\section{Table 2: Cognitive Styles [9]}

\begin{tabular}{l|l}
\hline \multicolumn{1}{c}{ LEVELS } \\
\hline Global & $\begin{array}{l}\text { Individual prefer to work with big ideas, however it } \\
\text { may lose perception of the details (can process } \\
\text { abstract information) }\end{array}$ \\
\hline Local & $\begin{array}{l}\text { Individual prefer work that demands keeping track } \\
\text { of details and concentrating on specific (requires } \\
\text { concrete details) }\end{array}$ \\
\hline
\end{tabular}

\begin{tabular}{l|l}
\hline \multicolumn{1}{c}{ SCOPES } \\
\hline Internal & $\begin{array}{l}\text { Individual is usually introvert and does not feel } \\
\text { comfortable in groups (prefers working } \\
\text { independently) }\end{array}$ \\
\hline External & $\begin{array}{l}\text { Individual avoids working and being alone (prefers } \\
\text { working with more people) }\end{array}$ \\
\hline
\end{tabular}

\begin{tabular}{l|l}
\hline \multicolumn{2}{c}{ LEANINGS } \\
\hline Liberal & $\begin{array}{l}\text { Individual may prefer change simply for the sake of } \\
\text { change, even when it is not ideal (goes beyond } \\
\text { boundaries) }\end{array}$ \\
\hline Conservative & $\begin{array}{l}\text { Individual likes to minimise change and avoid } \\
\text { ambiguity (prefers conventions and structures) }\end{array}$ \\
\hline
\end{tabular}

Considering the dimensions presented in Table 2, we classify them against the Design Thinking stages to find the empathy in each stage within the context of team collaboration. Table 3 is developed using ' - ' and '+' indicating lower and higher affinity of the respective styles to each of the stages of the Design Thinking Model. It tabularly represents the cognitive profiles that represent lower and higher empathy and best match the requirements of each stage.

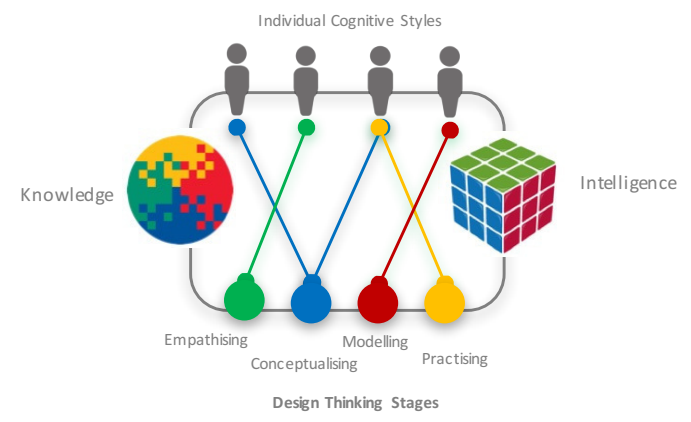

Figure. 6 Model of Cognitive Affinity with Design Thinking

TABle 3: EMPathy Foundation BETWEEn DESIGN ThinKING AND Cognitive Styles [9]

\begin{tabular}{|c|c|c|c|c|}
\hline $\begin{array}{c}\text { Design } \\
\text { Thinking } \\
\text { Stages }\end{array}$ & Empathising & $\begin{array}{c}\text { Concep- } \\
\text { tualising }\end{array}$ & $\begin{array}{c}\text { Model- } \\
\text { ling }\end{array}$ & Practising \\
\cline { 1 - 4 } $\begin{array}{c}\text { Individual } \\
\text { Styles }\end{array}$ & + & + & - & + \\
\cline { 1 - 4 } Global & - & + & + & + \\
\hline Local & + & - & - & + \\
\hline Internal & + & + & + & - \\
\hline External & - & & & \\
\hline & - & + & + & - \\
\hline Liberal & + & - & - & + \\
\hline Conservative & + & & & \\
\hline
\end{tabular}

\section{Design Thinking and Cognitive Empathy}

In order to create intellectual capital, the collective knowledge of individuals in an organisation needs to produce wealth, multiply output of physical assets, gain competitive advantage, and/or enhance the value of other types of capital. Using the cognitive dimension of Design Thinking in decentralised workforces, the target is to develop creatively confident groups that are able to trigger 
competitive value to transform multidisciplinary knowledge into valuable intellectual capital for organisations.

Design Thinking as a cognitive and intellectual process that balances the rational and emotional, when applied, harmonises with other modes of thinking and closes knowledge and information gaps, creating order and refining meaning. Because Design Thinking is a dynamic, constructive process that is iterative in nature, developing ideas requires ongoing definition, redefinition, representation and assessment. To achieve those tangible outcomes, it is necessary to open the process to multiple participants and to socialise the process and outcomes. Visualisation is a very critical part of the process, not an outcome [28].

Empathy provides a foundation for guiding our behaviours towards others [29]. Emotional empathy, also called affective empathy or primitive empathy, is the subjective state resulting from emotional contagion. Cognitive empathy is principally responsible for precisely recognise and comprehend another's expressive and emotional state. This kind of empathy is called sometimes "perspective taking."'[9]

Table 3 presents an individual cognitive foundation to empathise Design Thinking in a new decentralised dimension, considering:

- A human-centred discussion: to derive a point of view POV- (conceptualising).

- Fomenting a culture of prototyping: trying different models and ideas (modelling).

- Bringing theories to a real context: showing and not just telling (practising).

- Fomenting radical collaboration: listening to other people (empathising).

- Bias towards action: moving forward when knowing where to go (conceptualising).

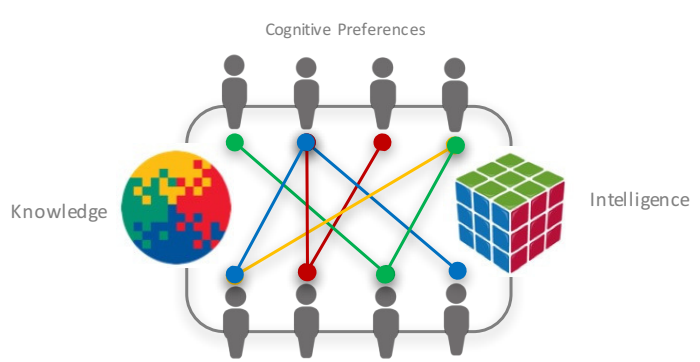

Figure. 7 Model of Individual Cognitive Empathy

\section{CYBER-COGNITIVE CONDITIONS}

A complementary and crucial, prerequisite to implement a collective intellectual capital model with decentralised workforces is the realisation that digital literacy means far more than just a number of technological skills. Rather, it is synonymous with a new cyber-humanism, which encompasses a variety of cognitive, motor, emotional, and sociological behavioural adaptations: competencies that enable people to function in digital environments.

The core is a complex mix of six basic components suggested by Eshet-Alkalai [30] and supported by empirical research.

- Photo-Visual Literacy

- Reproduction Literacy

- Branching Literacy Information

- Information Literacy

- Socio-Emotional Literacy

- Real-Time Thinking

These meta-competences are indispensable in an organisation that is constantly moving on several levels. They go hand in hand with a cyber-humanist paradigm shift: from technology to pedagogy. To this day, these six facets form the basic model for the understanding, creating and processing of digital content [31].

\section{A. Photo-Visual Literacy}

Digital communication now offers us the chance to reverse this "cognitive load", which is a way of going backwards. Because, in the digital age, image-improved communication significantly reduces the time required for interfacing with interfaces. Due to the low cognitive load, image processing functions almost automatically. Communicatively, it goes back to the cave.

\section{B. Reproduction Literacy}

Digitisation also allows a fundamental "persistence" of content. "Reproduction Literacy" describes the ability to create meaningful, authentic and creative works or interpretations that incorporate the existing: the art of creative recycling of existing material. The prerequisite for this is multidimensional synthetic thinking.

\section{Branching Literacy}

Knowledge must increasingly be constructed from large quantities of independent, disordered pieces of information. This requires the competence to be able to think in associative, branched and non-linear ways.

The intellectual source of this ability is the "Cognitive Flexibility Theory" [32]. In essence, it describes how individuals manage to spontaneously restructure their own knowledge and understand complexity meaningfully - a kind of hypermedia skill. Branched thinking is based on a sense of spatial multidimensional orientation. It prevents people from losing sight of reality when they move around in the "virtual" world. It also requires metaphorical thinking: the ability to create mental models and other representations [33].

\section{D.Information Literacy}

"Information Literacy" functions like a filter: it helps to identify erroneous, irrelevant or pre-existing information. It 
is the proverbial step on the perceptual brake. It prevents people from succumbing to the temptation to accept information as given, even if it appears "binding" and valid. It therefore concerns critical thinking and a permanent scepticism about the quality of information.

The transfer of these findings into the working world is as obvious as it is relevant: the diversity of perspectives and diversity of sources require a critical analysis of information, especially in the face of a perceived overload of information. What is missing is not necessarily the mental resources. Rather, it takes a kind of filter training to transfer the critical thinking into the world of information.

\section{E. Socio-Emotional Literacy}

The spread of digital communication platforms has opened up a multitude of new opportunities for collaborative learning and sharing of information. But with these new opportunities come new problems which were simply unknown before the digital era.

Outsourcing, Ideology, Self-awareness and Power are some examples of known problems. Competent users may know how to avoid these traps, and to focus on the benefits of digital communications. They practise a relatively new method of digital literacy: "Socio-Emotional Literacy". To acquire this, users must be critically, analytically mature and equipped with a high degree of Information Literacy and Branching Literacy. Investing in this ability will be crucial for business in the future.

\section{F. Real-Time Thinking}

"Real-Time Digital" sounds promising. And at the same time, it is the semantic cornucopia for the parallel bombardment of sound, text and image in the digital age. But it is our everyday life, and accordingly, the demand for the ability to process these different stimuli in parallel is commonplace.

The transition from digital literacy to cyber-humanism is much more than just dealing with digital technology. Really forward-looking is an all-embracing cyber-humanism which is at the same time a digital optimism, by learning to acquire digital competences.

Digital literacy becomes not only necessary for the effective transformation of knowledge, but also a consequence that supports sustainable creation of intellectual capital.

Figure 8 shows the proposed process of transformation (KI - Knowledge - Intelligence) presenting the sequence of patterns, models and resources necessary to accomplish the effective creation of intelligence as expression of intellectual capital.

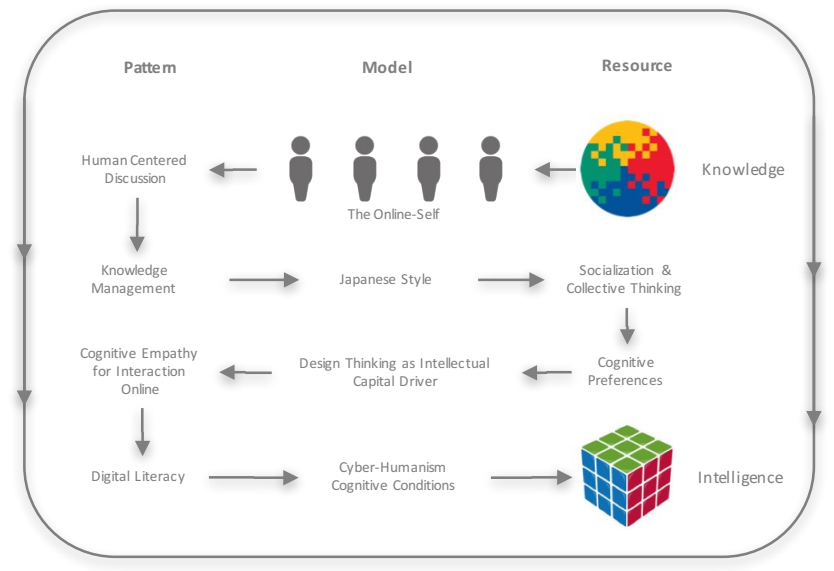

Figure. 8 Transformation Process Knowledge Intelligence

\section{CONCLUSION}

This study suggested how to combine models, methods, conditions and relevant cognitive aspects necessary to transform knowledge into intelligence considering the conditions of descentralized organizations.

Creation of intelligence as expression of intellectual capital in the digital age cannot be achieved merely through knowledge collection. A proper model is necessary to promote the exchange of human values and participation within collective-thinking environments. This is particularly important for organisations working with geographically distributed teams that are "missing" face-to-face interaction, and that are at high risk of having isolated members. They should be guided towards the implementation of working models, supported by methods like Design Thinking, not just for innovation and to create new products or services, but to embed them as a working philosophy, taking into consideration the relevance of the cognitive preferences of each individual. Creating intellectual capital should not be a project, but the continuous creative working environment for all members of the organisation that should become a habit.

The management of knowledge nowadays can be very complex and treat individuals unfairly, resulting in their isolation. However, digital literacy should be aligned not just to collect distributed knowledge but to build a cyberhumanistic cosmos, creating it as a collection, bearing in mind the wide spectrum of individuals' locations and their cognitive preferences.

\section{REFERENCES}

[1] Ackoff, Russell (1989). "From Data to Wisdom". Journal of Applied Systems Analysis. 16: 3-9.

[2] Mark, G. (2001) Meeting current challenges for virtually collocated teams: participation, culture, and integration. In Our Virtual World: the transformation of work, play and life via technology (Eds., Chidambaram, L. and Zigurs, I.) pp.74-93. Idea group publishing, Hershey USA.

[3] Jarvenpaa, S. L. \& Leidner, D. E. (1999) Communication and trust in global virtual teams. Organization Science, 10, 6, 791-815. 
[4] Ahuja, M. K., Galletta, D. F. \& Carley, K. M. (2003) Individua centrality and performance in virtual $R \& D$ groups: An empirical study. Management Science, 49, 1, 21-38.

[5] Paul, D. L. \& McDaniel Jr, R. R. (2004) A field study of the effect of interpersonal trust on virtual collaborative relationship performance. MIS Quarterly, 28, 2, 183.

[6] Alavi, M. \& Leidner, D.E. (2001) Review: knowledge management and knowledge management systems: conceptual foundations and research issues. MIS Quarterly, 25, 107-136.

[7] Allport, F. H. Lepkin , M. (1943), Building war morale with news headlines. Public Opinion Quarterly, 7, 211-221

[8] Daft, R.L. \& Lengel, R.H. (1986) Organizational information requirements, media richness and structural design. Management Science, 32, 554-571.

[9] Chujfi, S. Meinel, C. (2015), Patterns to explore cognitive preferences and potential collective intelligence empathy for processing knowledge in virtual settings. Springer Open. Journal of Interaction Science 2015 3:5.

[10] Ko, D.-G., Kirsch, L.J. \& King, W.R. (2005) Antecedents of knowledge transfer from consultants to clients in enterprise system implementations. MIS Quarterly, 29, 59-85.

[11] A. W Woolley, "Evidence for a Collective Intelligence Factor in the Performance of Human Groups" Science 330, 686 (2010);

[12] Bourdieu, Pierre. 1984. Distinction: A Social Critique of the Judgment of Taste. Cambridge MA: Harvard University Press. pp. 170, 466.

[13] Nonaka, I. Takeuchi H. The Knowledge-Creating Company. Oxford University Press. 1995. 197-199.

[14] Plattner, H, Meinel C., Weinberg U. (2009) 'Design Thinking', FinanzBuch Verlag München.

[15] Smith, M. K. (2003) 'Michael Polany and tacit knowledge', the encyclopedia of informal education, http://infed.org/mobi/michaelpolanyi-and-tacit-knowledge/. Retrieved: 13. Nov 2016

[16] Wilson, T. (2002) "The nonsense of "knowledge management", Information Research, vol. 5, paper no. 144

[17] De Bono, E. (2000). Thinking Course, Great Britain: BBC Book.

[18] Dunn, Kenneth, and Rita Dunn, "Dispelling Outmoded Beliefs aboutStudent Learning" Educational Leadership, March, 1987.

[19] Stout, R. J., Cannon-Bowers, J. A., Salas, E., \& Milanovich, D. M (1999). Planning, shared mental models, and coordinatedperformance: An empirical link is established. Human Factors, 41, 61-71.

[20] Volkma, R. J., \& Gorman, R. H. (1998). The influence of cognitivebased group composition on decision-making process and outcome. Journal of Management Studies, 35, 105-121.
[21] Heald, M. R., Contractor, N. S., Koehly, L. M., \& Wasserman, S. (1998). Formal and emergent predictors of coworkers perceptual congruence on an organizations social structure. Human Communication Research, 24, 536-563.

[22] Baruch, Y., \& Nicholson, N. (1997). Home, sweet work: Requirements for effective home working. Journal of General Management, 23, 15-31.

[23] Hill, E. J., Miller, B. C., Weiner, S. P., \& Colihan, J. (1998). Influences of the virtual office on aspects of work and work/life balance. Personnel Psychology, 51, 667-683.

[24] Wieland, R. (1999). Mental workload in VDU-assisted office work: Consequences for the design of telework. Zeitschrift Fur Arbeits-Und Organisationaspsychologie, 43, 153-158.

[25] Ferrari, M., \& Sternberg, R. J. (1998). The development of mental abilities and styles. In W. Damon, D. Kuhn, \& R. S. Siegler (Eds.), Handbook of child psychology: Vol. 2 (5th ed., pp. 899-946). NY: Wiley.

[26] Jehng, J. J. (1997). The psycho-social processes and cognitive effects of peer-based collaborative interactions with computers. Journal of Educational Computing Research, 17, 19-46.

[27] Workman, M., Kahnweiler, W., \& Bommer, W. H. (2003). The effects of cognitive style and technology media on commitment to telework and virtual teams, Journal of Vocational Behavior, 63, 199-21.

[28] Mootee, Idris. (2012) 'Design Thinking Is A Cognitive And Intellectual Process That Balances The Rational And Emotional', $\mathrm{http}$ ://idr.is/design-thinking-is-a-cognitive-and-intellectual-processthat-balances-the-rational-and-emotional-not/. Retrieved: 13. Nov 2016

[29] Rogers, Kimberley, Isabel Dziobek, Jason Hassenstab, Oliver T. Wolf, and Antonio Convit. "Who cares? Revisiting empathy in Asperger syndrome." Journal of Autism and Developmental Disorders 37, no. 4 (2007): 709-715.

[30] Eshet-Alkalai, Yoram (2004): Digital Literacy: A Conceptual Framework for Survival Skills in the Digital Era. Journal of Educational Multimedia and Hypermedia (2004) 13 (1), 93-106

[31] Naughton, C. (2016): Digitale Erleuchtung: "Cyber-Humanismus: Digitale Ermächtigung". Zukunftsinstitut GmbH, 58-65.

[32] Spiro, R. J., Feltovich, P. J., Jacobson, M. J., \& Coulson, R. L. (1992). Cognitive flexibility, constructivism and hypertext: Random access instruction for advanced knowledge acquisition in ill-structured domains. In T. Duffy \& D. Jonassen (Eds.), Constructivism and the Technology of Instruction. Hillsdale, NJ: Erlbaum.

[33] Eshet-Alkalai, Yoram \& Amichai-Hamburger Yair (2004). Experiments in Digital Literacy. CyberPsychology \& Behaviour, 7(4), 425-434. 